\title{
Chronic Suppression of Inositol 1,4,5-Triphosphate Receptor-Mediated Calcium Signaling in Cerebellar Purkinje Cells Alleviates Pathological Phenotype in Spinocerebellar Ataxia 2 Mice
}

\author{
Adebimpe W. Kasumu, ${ }^{1}$ Xia Liang, ${ }^{1}$ Polina Egorova, ${ }^{2}$ Daria Vorontsova, ${ }^{2}$ and Ilya Bezprozvanny ${ }^{1,2}$ \\ ${ }^{1}$ Department of Physiology, University of Texas Southwestern Medical Center, Dallas, Texas 75390, and 2Laboratory of Molecular Neurodegeneration, \\ Department of Medical Physics, St. Petersburg Technical University, 195251 St. Petersburg, Russia
}

\begin{abstract}
Spinocerebellar ataxia 2 (SCA2) is a neurodegenerative disorder characterized by progressive ataxia. SCA2 results from a poly $(\mathrm{Q})$ (polyglutamine) expansion in the cytosolic protein ataxin-2 (Atx2). Cerebellar Purkinje cells (PCs) are primarily affected in SCA2, but the cause of PC dysfunction and death in SCA2 is poorly understood. In previous studies, we reported that mutant but not wild-type Atx2 specifically binds the inositol 1,4,5-trisphosphate receptor $\left(\operatorname{InsP}_{3} \mathrm{R}\right)$ and increases its sensitivity to activation by InsP $\mathrm{P}_{3}$. We further proposed that the resulting supranormal calcium $\left(\mathrm{Ca}^{2+}\right)$ release from the PC endoplasmic reticulum plays a key role in the development of SCA2 pathology. To test this hypothesis, we achieved a chronic suppression of $\operatorname{InsP}_{3} \mathrm{R}_{\text {-mediated }} \mathrm{Ca}^{2+}$ signaling by adenoassociated virusmediated expression of the inositol 1,4,5-phosphatase (Inpp5a) enzyme (5PP) in PCs of a SCA2 transgenic mouse model. We determined that recombinant 5PP overexpression alleviated age-dependent dysfunction in the firing pattern of SCA2 PCs. We further discovered that chronic 5PP overexpression also rescued age-dependent motor incoordination and PC death in SCA2 mice. Our findings further support the important role of supranormal $\mathrm{Ca}^{2+}$ signaling in SCA2 pathogenesis and suggest that partial inhibition of Ins $\mathrm{P}_{3}$-mediated $\mathrm{Ca}^{2+}$ signaling could provide therapeutic benefit for the patients afflicted with SCA2 and possibly other SCAs.
\end{abstract}

\section{Introduction}

Spinocerebellar ataxia type 2 (SCA2) is an autosomal-dominant neurodegenerative disorder characterized in patients by a progressive incoordination of movement known as ataxia. SCA2 patients also present with other secondary symptoms including dysarthria, dysphagia, delayed saccadic eye movements, and peripheral neuropathy (Lastres-Becker et al., 2008). Autopsy studies of SCA2 patients consistently show olivopontocerebellar atrophy with marked reduction of Purkinje cells (PCs), degeneration of the inferior olives, pontine nuclei, and pontocerebellar fibers (Geschwind et al., 1997; Lastres-Becker et al., 2008). Atro-

Received April 3, 2012; revised June 27, 2012; accepted July 25, 2012.

Author contributions: A.W.K. and I.B. designed research; A.W.K., X.L.,P.E., and D.V. performed research; A.W.K., P.E., and D.V. analyzed data; A.W.K. and I.B. wrote the paper.

This work was supported by NIH Grants R01 NS056224, R01 NS38082, and R01 NS074376 (I.B.) and by Russian Ministry of Science Contract 14.740.11.0924 (I.B.). A.W.K. is a Howard Hughes Medical Institute Med into Grad scholar. I.B. is a holder of the Carl J. and Hortense M. Thomsen Chair in Alzheimer's Disease Research. We thank Ying Li for help with electrophysiological experiments and Leah Taylor for administrative assistance. We thank Stefan Pulst (University of Utah) for generously providing us with SCA2 mouse model and Dr. Masamitsu lino (University of Tokyo) for generously providing 5PP expression constructs. We thank Dr. Beverly Davidson, Maria L. Scheel, and the staff of the University of lowa Gene Transfer Vector Core for help with AAV production. We thank Dr. Melanie Mark (Ruhr University Bochum) and Drs. Tom Otis and Meera Pratap (University of California, Los Angeles) for advice on electrophysiological recordings. We thank Stefan Pulst and Tom 0tis for comments on this manuscript.

The authors declare no competing financial interests.

Correspondence should be addressed to Dr. llya Bezprozvanny, Department of Physiology, University of Texas Southwestern at Dallas, Dallas, TX 75390. E-mail: ilya.bezprozvanny@utsouthwestern.edu.

DOI:10.1523/JNEUROSCI.1643-12.2012

Copyright $@ 2012$ the authors $\quad 0270-6474 / 12 / 3212786-11 \$ 15.00 / 0$ phy of the cerebellum and brainstem in SCA2 patients can also be visualized in vivo by MRI (Bürk et al., 1996). SCA2 is one of the most prevalent dominantly inherited SCAs in a heterogeneous group of 30 spinocerebellar ataxias. Each SCA is linked to a mutation, deletion, or polyglutamine expansion at a different gene locus. SCA2 has been genetically linked to an expansion and translation of an unstable CAG repeat track in the gene that codes for ataxin-2 (ATXN2) (Imbert et al., 1996; Pulst et al., 1996; Sanpei et al., 1996). In SCA2 patients, the repeat track is expanded from the normal 22 glutamine repeats (Atx2-22Q) to $>58$ (Atx2$58 \mathrm{Q})$ glutamine repeats. The cause of PC degeneration in SCA2 is currently unknown (Bezprozvanny and Klockgether, 2010).

We previously reported that Atx2-58Q, but not Atx2-22Q, specifically interacts with and increases the sensitivity of inositol 1,4,5-triphosphate receptors ( $\mathrm{InsP}_{3} \mathrm{Rs}$ ) to activation by $\mathrm{InsP}_{3}$ (Liu et al., 2009). This was supported by our experiments in primary PC cultures from SCA2-58Q transgenic mice that express Atx2-58Q under the control of the PC-specific promoter (Huynh et al., 2000). When compared with PC cultures from their wild-type littermates, SCA2-58Q PC cultures treated with an mGluR agonist DHPG [(RS)-3,5-dihydroxyphenylglycine] exhibited significantly greater Ins $\mathrm{P}_{3}$-induced calcium $\left(\mathrm{Ca}^{2+}\right)$ release (IICR) from the endoplasmic reticulum (ER) and higher intracellular $\mathrm{Ca}^{2+}$ concentrations (Liu et al., 2009). Moreover, we demonstrated that long-term feeding of SCA2-58Q mice with $\mathrm{a} \mathrm{Ca}^{2+}$ stabilizer (dantrolene) alleviated the motor phenotype of these mice and reduced PC loss (Liu et al., 2009). Based on these 
findings, we proposed that the association of polyglutamineexpanded ataxin-2 with $\mathrm{InsP}_{3} \mathrm{Rs}$ results in excessive $\mathrm{Ca}^{2+}$ release from the PC ER and initiates cytoplasmic $\mathrm{Ca}^{2+}$ dysregulation and cellular dysfunction of PCs, which eventually result in ataxia (Liu et al., 2009; Kasumu and Bezprozvanny, 2012). In support of our hypothesis, genetic evidence has been used by others to suggest that $\mathrm{Ins}_{3} \mathrm{R}$ is in the "eye of the storm" of pathogenesis for many SCAs (Schorge et al., 2010).

To further test our hypothesis in the present study, we used a specific molecular intervention to normalize $\operatorname{Ins}_{3} \mathrm{R}$-mediated $\mathrm{Ca}^{2+}$ signals in PCs of SCA2-58Q mice. Consistent with our hypothesis, we discovered that partial suppression of IICR in SCA2-58Q mice prevented the onset of PC dysfunction, alleviated motor incoordination, and reduced age-dependent PC degeneration in SCA2-58Q mice. These results indicate that partial suppression of IICR is a viable therapeutic strategy for treatment of SCA2 and possibly other SCAs.

\section{Materials and Methods}

SCA2-58Q mouse colony. SCA2-58Q mice on C57/B6 background (Huynh et al., 2000) were kindly provided to our laboratory by Dr. Stefan Pulst (University of Utah, Salt Lake City, UT) and used in our previous studies (Liu et al., 2009). In these mice, the expression of human Atx2$58 \mathrm{Q}$ transgene is driven by the $\mathrm{PC}$-specific L7/pcp2 promoter (Huynh et al., 2000). The mice were backcrossed to FVB/N background for at least six generations in our laboratory and used in the previous study (Kasumu and Bezprozvanny, 2012). In this study, the SCA2-58Q (FVB) male hemizygous mice were bred to wild-type (WT) FVB/N females to generate mixed litters. The pups were genotyped by PCR for the presence of human Atx 2 transgene and parallel experiments were performed with transgenic and wild-type littermates. All mice were housed in a temperature-controlled room at $22-24^{\circ} \mathrm{C}$ with a $12 \mathrm{~h}$ light/dark cycle. Mice had access to standard chow and water ad libitum. All procedures were approved by the Institutional Animal Care and Use Committee of the University of Texas Southwestern Medical Center at Dallas in accordance with the National Institutes of Health Guidelines for the Care and Use of Experimental Animals.

Cerebellar slice recordings. Cerebellar slices were prepared from WT and SCA2 mice at 6, 12, 24, 36, and 48 weeks of age. Mice were anesthetized with a ketamine/xylazine mixture and transcardially perfused with ice-cold aCSF containing the following (in $\mathrm{mm}$ ): $85 \mathrm{NaCl}, 24 \mathrm{NaHCO}_{3}$, 25 glucose, $2.5 \mathrm{KCl}, 0.5 \mathrm{CaCl}_{2}, 4 \mathrm{MgCl}_{2}, 1 \mathrm{NaH}_{2} \mathrm{PO}_{4}$, 75 sucrose. Solutions were equilibrated with $95 \% \mathrm{O}_{2} / 5 \% \mathrm{CO}_{2}$. Subsequently, the cerebellum was dissected and 300- $\mu \mathrm{m}$-thick sagittal slices were made with a VT1200S vibratome (Leica). Slices were allowed to recover in aCSF at $35^{\circ} \mathrm{C}$ for $30 \mathrm{~min}$ and then transferred to room temperature before recordings were made. All recordings were made within $5 \mathrm{~h}$ after dissection. Recordings were made in a chamber (Warner Instruments) heated to $34-35^{\circ} \mathrm{C}$. Loose-patch recordings were made (Häusser and Clark, 1997; Smith and Otis, 2003) to evaluate spontaneous activity of PCs from WT and SCA2 mice at different ages. Briefly, the patch pipette was filled with $140 \mathrm{~mm} \mathrm{NaCl}$ buffered with $10 \mathrm{~mm}$ HEPES, pH 7.3, held at $0 \mathrm{mV}$. A loose patch $(<100 \mathrm{M} \Omega)$ was generated at the PC soma close to the axon hillock. Extracellular recording solution contained the following (in $\mathrm{mm}$ ): 119 $\mathrm{NaCl}, 26 \mathrm{NaHCO}_{3}, 11$ glucose, $2.5 \mathrm{KCl}, 2.5 \mathrm{CaCl}_{2}, 1.3 \mathrm{MgCl}_{2}, 1$ $\mathrm{NaH}_{2} \mathrm{PO}_{4}$. In some experiments, recordings were performed in the presence of $100 \mu \mathrm{M}$ picrotoxin (Sigma-Aldrich) and $10 \mu \mathrm{M}$ DNQX (SigmaAldrich) to verify spontaneous nature of observed events. Spontaneous action potential currents were recorded for at least $5 \mathrm{~min}$ from each cell. These $5 \mathrm{~min}$ recordings were analyzed for tonic or burst firing patterns. A PC was characterized as firing tonically if it was found to fire repetitive tonic spikes with relatively constant frequency during the recording duration. A cell was characterized as bursting if it was identified that it had $>5 \%$ of the interspike intervals that fell outside of 3 SDs from the mean of all interspike intervals in that cell. The proportion of tonically firing PCs for each genotype at each time point was calculated and plotted as mean percentage of total PCs recorded $\pm \mathrm{SE}$. All tonically firing PCs were analyzed further for firing frequency (FF) and firing variability (Alviña and Khodakhah, 2010a,b). The mean firing frequency in the $5 \mathrm{~min}$ recording duration was calculated for each PC, and the average firing frequency for each genotype at each time point was also calculated and plotted as mean \pm SE. The correlation of variation of interspike interval (CV ISI) was calculated to represent the firing variability. We calculated CV ISI as the SD divided by the mean interspike interval in a $5 \mathrm{~min}$ recording period for each PC. To test the acute effects of blocking $\mathrm{InsP}_{3}-\mathrm{Ca}^{2+}$ signaling on PC dysfunction in SCA2 mice, we treated spontaneously firing 24-week-old 58Q PCs with an mGluR1 antagonist, (+)-2-methyl-4-carboxyphenylglycine (LY367385) (SigmaAldrich). These recordings were made in the presence of $100 \mu \mathrm{M}$ picrotoxin and $10 \mu \mathrm{M}$ DNQX to block fast excitatory and inhibitory transmission. PCs were recorded in the absence of LY367385 for at least 5 min and then treated with $100 \mu \mathrm{M} \mathrm{LY367385}$ for the remainder of the recording (at least $8 \mathrm{~min}$ ). The average firing rate and average CV ISI was analyzed in the 2 min immediately before treatment with LY367385 and 3 min after the addition of $100 \mu \mathrm{M}$ LY367385.

Adenoassociated virus production. The wild-type and mutant (R343A and R343A/R350A) mouse inositol 1,4,5-triphosphate 5-phosphatase (Inpp5a; 5PP) expression constructs were kindly provided to us by Dr. Masamitsu Iino [University of Tokyo, Tokyo, Japan (Kanemaru et al., 2007)]. A hemagglutinin (HA) tag was added to the $\mathrm{N}$ terminus of each $5 \mathrm{PP}$ construct by PCR. The HA-5PP inserts were excised and individually cloned into the pFBGR (pGANCMVBGHpA) plasmid behind the CMV promoter. The inserts now including a CMV promoter were individually cloned into a pAAV plasmid. The pAAV plasmid also expresses GFP driven by a different CMV promoter. The AAV-5PP plasmids were sent to the University of Iowa Gene Transfer Vector Core where serotype 1 adenoassociated viruses (AAVs) were made using the Sf9 cell-based AAV production system. The titer of purified AAV-5PP viruses provided by the University of Iowa Gene Transfer Vector Core was $\geq 10^{13}$ infectious particles/ml. In addition, control AAV-GFP virus of similar titer was also provided by the University of Iowa Gene Transfer Vector Core.

Calcium imaging in mouse embryonic fibroblast cells. Presenilin double knock-out mouse embryonic fibroblast (PS DKO MEF) cells (Herreman et al., 2000) were used to determine the efficacy of the AAV-5PP constructs to suppress $\mathrm{InsP}_{3}$-induced $\mathrm{Ca}^{2+}$ release. Due to the absence of presenilins 1 and 2, these MEF cells have high $\mathrm{ER} \mathrm{Ca}^{2+}$ levels that can be released via $\mathrm{InsP}_{3} \mathrm{Rs}$ with the application of $300 \mathrm{~nm}$ bradykinin (BK) $(\mathrm{Tu}$ et al., 2006). Briefly, MEF cells were cultured on poly-D-lysine (SigmaAldrich)-coated $12 \mathrm{~mm}$ round glass coverslips and infected with AAV5PP, AAV-RA, AAV-DM, or AAV-GFP. Cytosolic $\mathrm{Ca}^{2+}$ imaging experiments in $\mathrm{Ca}^{2+}$-free media were performed $48 \mathrm{~h}$ after viral infection using a fura-2 fluorescent indicator as previously described (Tu et al., 2006). Infected MEF cells were identified by GFP fluorescence and the fura-2 data were collected.

Adenoassociated viral injection. Stereotaxic surgery was performed according to the study by Dodge et al. (2005). Briefly, $4 \mu \mathrm{l}$ of AAV $\left(10^{13}\right.$ titer) was bilaterally injected into the deep cerebellar nucleus (DCN) at the coordinates (in $\mathrm{mm}$ ) of bregma, -5.75 ; lateral, +1.8 ; dorsoventral, -2.6. PCs project axons into the DCN and retrogradely transport the virus back to the soma where it integrates and is expressed for $>12$ months (Kaemmerer et al., 2000; Dodge et al., 2005). AAV GFP expression in PCs was confirmed by scanning cerebellar slices with a fluorescence plate reader or confocal imaging. HA-tag expression was confirmed by Western blotting of cerebellar lysates at least 2 weeks after surgery. Infection efficiency was calculated by comparing transduced PCs to PCs from L7-GFP transgenic mice, which express GFP in all PCs driven by the $\mathrm{L} 7 / \mathrm{pcp} 2 \mathrm{PC}$-specific promoter.

Western blotting. Cell lysates were prepared from infected MEF cell cultures and from cerebellum of mice post-DCN injection. The expression of AAV-5PP, AAV-RA, AAV-DM was confirmed by probing with monoclonal antibodies against 5PP (clone 3D8; Sigma-Aldrich) and HAtag (clone HA-7; Sigma-Aldrich). Monoclonal antibodies against actin were used as a loading control (clone AC-15; Sigma-Aldrich).

Motor coordination assessments in mice. Rotarod and beam walk assays were used to assess motor coordination. These were performed as previously described (Liu et al., 2009). For analysis of motor impairment, 
female mice from each litter were genotyped, weight-matched, and divided into three WT and three SCA2-58Q groups, with each group containing 13-19 mice each. Briefly, SCA2-58Q and WT mice were trained on the accelerating rotarod apparatus (Columbus Instruments). Mice were screened on the rotarod running at a constant speed of $5 \mathrm{rpm}$. Mice that fell off the rod in $<5$ min were dismissed. At each time point following baseline testing, mice were trained on the rotarod accelerating at $0.2 \mathrm{rpm}$ for 4 consecutive days with three trials per day. The mean latency to fall off the accelerating rod on day 4 was recorded and analyzed for every animal in all six groups. Average group latency was calculated and plotted for all time points. Three days after rotarod testing, mice were tested on the beam walk assay using a homemade apparatus. Mice were trained on 3 consecutive days, with three consecutive trials on three separate beams of differing diameters. A round plastic $17 \mathrm{~mm}$ beam, a round plastic 11 $\mathrm{mm}$ beam, and a wooden square $5 \mathrm{~mm}$ beam were used. The mean latencies to traverse the middle $80 \mathrm{~cm}$ length of the 11 and $5 \mathrm{~mm}$ beams on the third day were recorded and analyzed for every animal in all six groups. The average group latency and average number of foot slips were calculated and plotted for all time points as mean $\pm \mathrm{SE}$. These motor coordination tasks were performed at $4,6,8,10$, and 12 months of age. Mice that were found at the 4 month time point to be severely impaired on both behavioral tasks due to surgery-induced irreversible motor deficits were excluded from the entire study. These included two mice in the WT-DM group, three from the WT-RA group, three mice from the 58Q-DM group, and three mice from the 58Q-RA group.

Dark cell degeneration analysis. Analysis of PC dark cell degeneration (DCD) was performed as previously described (Kasumu and Bezprozvanny, 2012). Briefly, six mice per group were killed after the analysis of the 12 month motor tasks. Mice were killed and transcardially perfused [according to the study by Custer et al. (2006)] with PBS followed by $2 \%$ paraformaldehyde $2 \%$ glutaraldehyde in $0.1 \mathrm{~m}$ cacodylate buffer. The cerebellum was left in fixative overnight. The next day, the cerebellum was cut into $1 \mathrm{~mm}^{3}$ sagittal sections and postfixed in $1 \%$ osmium tetroxide. The specimen were subsequently stained en bloc with aqueous $1 \%$ uranyl acetate and lead citrate, dehydrated through a graded ethanol series, and embedded in EMbed 812 resin. Each cerebellum was cut into thinner sections ( $\sim 70-90 \mathrm{~nm}$ in thickness) and placed on copper grids. The grids were stained with aqueous $2 \%$ uranyl acetate and lead citrate. Two grids from each animal were examined on a FEI Tecnai G2 Spirit Biotwin transmission electron microscope operated at $120 \mathrm{kV}$. Digital images were captured with a SIS Morada 11 megapixel side mount CCD camera. At least six mice were analyzed per group with two grids produced from different cerebellum areas of the same mouse. PCs were judged to be in one of three stages—normal, moderate, or severe. Normal PCs are spherical in shape and have regular alignment in the PC layer. Moderately degenerated PCs have slight shrinkage and moderately electron-dense cytosol that is not as dark as the nucleus. Severely degenerated PCs have markedly shrunken and electron-dense cytosol with similarly darkened nucleus. These PCs are also not regularly aligned in the PC layer. The processing of cerebellar sections for DCD was performed by an independent investigator in the Electron Microscopy core at the University of Texas Southwestern Medical Center at Dallas, who was blinded to mouse genotype and treatment. DCD quantification was performed by an investigator that was blinded to mouse genotype and treatment. The percentage of normal, moderately degenerated, and se-
Tonic

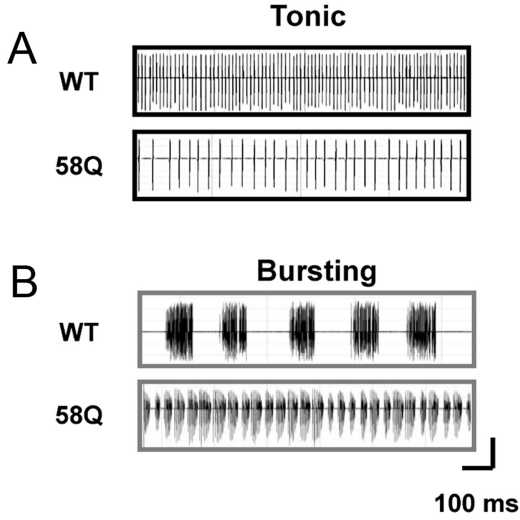

$100 \mathrm{~ms}$

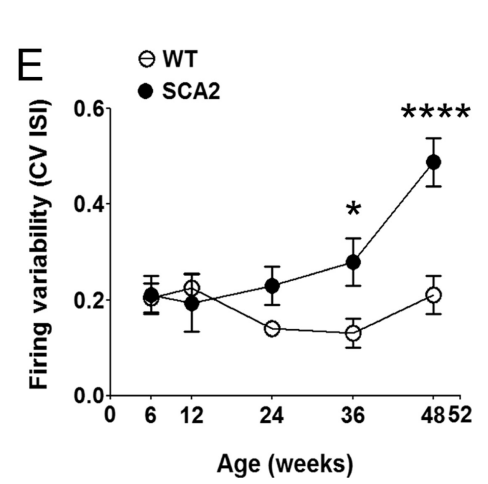

C

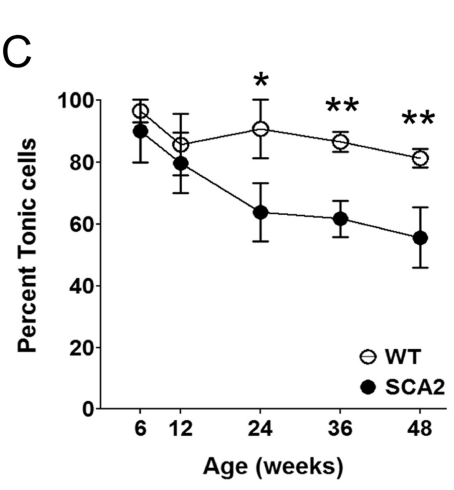

Age (weeks)
Figure 1. Spontaneous activity of Purkinje cells in wild-type and SCA2-580 mice. Spontaneous firing activity was analyzed in 6-, 2-, 24-,36-, and 48-week-old WT and 580 PCS. PC firing was classified as tonic $(\boldsymbol{A})$ or bursting $(\boldsymbol{B})$ based on a 5 min recording

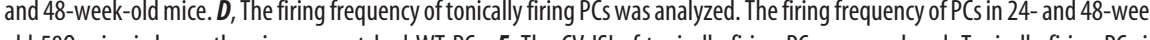
old 580 mice is lower than in age-matched WT PCS. E, The CV ISI of tonically firing PCs was analyzed. Tonically firing PCs in verely degenerated PCs in each mouse was calculated. The average percentage of each group was plotted as mean \pm SE.

Statistical analyses. Differences between specific groups were judged by a two-tailed Student unpaired $t$ test using a significance level of $p<0.05$.

\section{Results}

Progressive dysfunction of Purkinje cells in SCA2-58Q mice

PCs are the sole output of the cerebellar cortex, and the disruption of PC activity impairs cerebellar function in SCAs (Alviña and Khodakhah, 2010a,b; Mark et al., 2011; Shakkottai et al., 2011; Kasumu and Bezprozvanny, 2012). Recent studies demonstrated significantly reduced firing frequency of PCs in aging SCA2-127Q mice (S. Hansen, P. Meera, T. Otis, S. Pulst, unpublished observations). To evaluate the functional state of PCs in SCA2-58Q (58Q) mice, we used well established protocols (Smith and Otis, 2003; Walter et al., 2006; Mark et al., 2011; Shakkottai et al., 2011) to record spontaneous PC firing pattern in cerebellar slices obtained from the 6-, 12-, 24-, 36-, and 48week-old 58Q mice and from the age-matched WT littermates. In each experiment, the PCs were classified as firing in a tonic or bursting pattern during a $5 \mathrm{~min}$ recording period. The firing pattern of a PC was classified as tonic if it consisted of rarely halting tonic spikes with relatively constant frequency (Fig. 1A). A cell was characterized as bursting if it was identified that it had $>5 \%$ of the interspike intervals that fell outside of 3 SDs from the mean of all interspike intervals in that cell (Fig. $1 B$ ). From analysis of the data, we discovered that $>80 \%$ of PC cells fire in tonic firing pattern in slices obtained from 6 - and 12 -week-old mice for both 58Q and WT groups (Fig. 1C). To analyze these data further, 
A

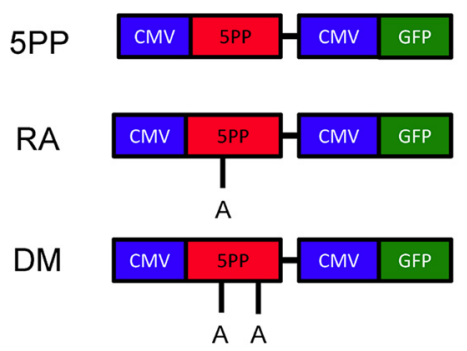

C

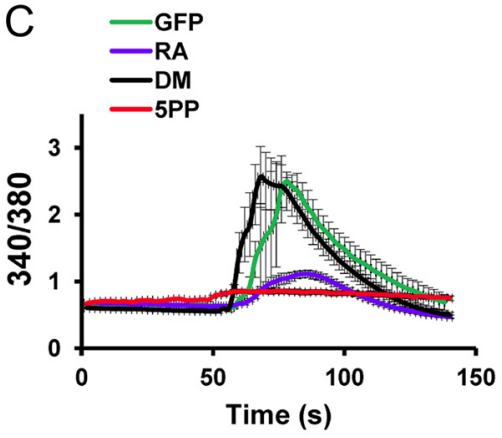

$0 \mathrm{mM} \mathrm{Ca}{ }^{2+}$

300 nM BK

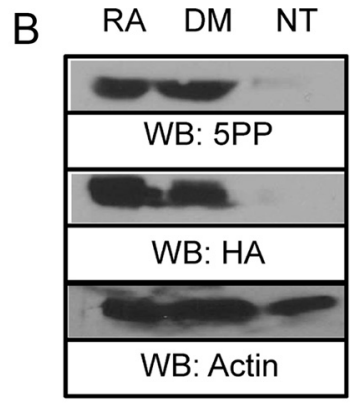

D

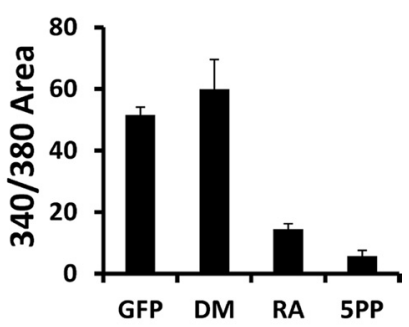

Figure 2. Generation and validation of AAV-5PP viruses. $\boldsymbol{A}$, Cloning strategy for AAV-5PP, AAV-RA, AAV-DM plasmids. The construct expresses 5PP and GFP, both driven by individual CMV promoters. $\boldsymbol{B}$, Western blotting of MEF cells infected with $10^{13}$ infectious particles/well AAV-5PP, AAV-RA, AAV-DM viruses. Lysates were prepared and analyzed by Western blotting with anti5PP, anti-HA, and anti-actin antibodies. C, MEF cell cultures infected with AAV-5PP, AAV-RA, and AAV-DM were loaded with fura- 2 . Basal fura-2 ratio recordings were collected for $55 \mathrm{~s}$. Bradykinin ( $300 \mathrm{~nm}$ ) was added to stimulate BK-coupled IP $\mathrm{P}_{3}$-induced calcium release. Fura- 2 ratio recordings were collected for 2 min to analyze the effect of AAV-5PP, AAV-RA, and AAV-DM on IP ${ }_{3}$-induced calcium release. The results are combined from three different batches of cells and shown as mean 340/380 ratio area SE. D, Fura-2 peak 340/380 ratios in cells expressing RA and 5PP are significantly lower than in cells expressing DM or GFP.

we determined the mean firing rates and the mean CV ISI for all tonically firing PCs in both groups of mice. We discovered that both the firing frequency and the variability of interspike intervals were similar for $58 \mathrm{Q}$ and WT mice at 6 and 12 weeks of age (Fig. 1D,E). From these results, we concluded that PCs function properly in 6 and 12 weeks $58 \mathrm{Q}$ mice, consistent with the lack of overt phenotype of $58 \mathrm{Q}$ mice at these ages in motor coordination assays (Liu et al., 2009).

In contrast to the results obtained with slices from the young WT and 58Q mice, the fraction of tonically firing PCs was significantly lower in $58 \mathrm{Q}$ mice than in WT mice at 24 weeks of age (Fig. 1C). On average, $91 \pm 10 \%(n=4$ mice $)$ of WT PCs and only $64 \pm 9 \%$ ( $n=7$ mice) of 58 Q PCs were firing tonically at this age $(p<0.05$; Fig. $1 C)$. Moreover, at 24 weeks of age, the tonically firing PCs in slices from the 58Q mice were firing less frequently that the tonically firing PCs in WT mice at the same age (Fig. 1D). On average, tonically active WT cells were firing at $51 \pm 3.3 \mathrm{~Hz}$ ( $n=19$ neurons) and tonically active 58Q cells were firing at $37 \pm 3.1 \mathrm{~Hz}(n=41$ neurons) at this age $(p<0.01$; Fig. $1 D)$. The variability of interspike intervals was not significantly different between $58 \mathrm{Q}$ and WT mice at this age (Fig. $1 E$ ). These results were replicated in recordings made from 36-week-old mice. The fraction of tonically firing PCs was reduced to $87 \pm 3 \%(n=2$ mice) in WT mice and to $62 \pm 6 \%(n=3$ mice $)$ in $58 \mathrm{Q}$ mice ( $p<$ 0.01 ; Fig. $1 C$ ). Furthermore, the firing frequency of these tonically firing WT cells remained relatively constant at $58 \pm 6.8 \mathrm{~Hz}$ ( $n=14$ neurons), and as expected, the firing frequency of $58 \mathrm{Q}$ PCs was further reduced to $29 \pm 3.9 \mathrm{~Hz}(n=22$ neurons; $p<$
0.001; Fig. 1D). We also found that the variability of interspike intervals (CV ISI) for tonically firing 58Q PCs was significantly increased $0.28 \pm 0.05$ ( $n=22$ neurons) compared with WT PCs (0.13 \pm $0.03 ; n=14 ; p<0.05$; Fig. $1 D$ ).

The functional differences between $58 \mathrm{Q}$ and WT mice became even more dramatic with increased age. When slices from 48-week-old mice were used, the fraction of tonically firing PCs was reduced to $76 \pm 4 \%$ ( $n=4$ mice $)$ in WT mice and to $56 \pm 10 \%(n=3$ mice $)$ in $58 \mathrm{Q}$ mice $(p<0.01$; Fig. $1 C)$. For tonically firing cells, the firing frequency of WT cells remained relatively constant at $55 \pm 3.7 \mathrm{~Hz}(n=24$ neurons $)$, but for $58 \mathrm{Q}$ cells the frequency of firing was further reduced to $25 \pm 6.3 \mathrm{~Hz}$ ( $n=13$ neurons; $p<0.001$; Fig. $1 D$ ). Moreover, at 48 weeks of age, the variability of interspike intervals (CV ISI) for tonically firing cells remained constant for WT cells at $0.20 \pm$ $0.03(n=24)$ but was significantly increased to $0.49 \pm 0.05$ ( $n=13$ neurons) for $58 \mathrm{Q}$ cells $(p<0.0001$; Fig. $1 D)$. Thus, we concluded that aging 58Q PCs increasingly fire in a bursting pattern and even tonically firing cells fire less frequently and with reduced precision when compared with age-matched WT cells. Interestingly, the age of onset of 58Q PCs electrophysiological abnormalities at 24 weeks of age (Fig. 1C,D) closely mirrors the age of onset of behavioral symptoms in SCA2-58Q mice in motor coordination assays observed in our previous studies (Liu et al., 2009). Based on this coincidence, we suggest that the reduced precision in PC firing in SCA2-58Q mice is causing the impaired performance of these mice in motor coordination tasks starting at 24 weeks of age. The continuous breakdown of the PC firing pattern at older ages (Fig. 1C-E) is likely to cause a progressive worsening of the motor incoordination phenotype of aging SCA2-58Q mice in motor coordination assays (Liu et al., 2009).

\section{$5 \mathrm{PP}$ overexpression suppresses $\mathrm{Ins}_{3}$-induced $\mathrm{Ca}^{2+}$ release}

To determine the importance of excessive $\mathrm{InsP}_{3} \mathrm{R}$-mediated $\mathrm{Ca}^{2+}$ release from the ER for SCA2 pathogenesis, we chose to chronically suppress IICR in PCs from $58 \mathrm{Q}$ mice. To specifically achieve this, we used serotype $1 \mathrm{AAVs}$ to stably express mouse Inpp5 (5PP) in PCs of 58Q mice. InsP $\mathrm{P}_{3}$-mediated $\mathrm{Ca}^{2+}$ release from the ER is triggered in response to generation of a cytosolic second messenger InsP $\mathrm{P}_{3}$. The $5 \mathrm{PP}$ enzyme converts $1,4,5-\mathrm{InsP}_{3}$ to an inactive form 1,4-Ins $\mathrm{P}_{2}$ and terminates the $\mathrm{InsP}_{3}$-induced $\mathrm{Ca}^{2+}$ signals. It has been previously demonstrated that stable overexpression of recombinant 5PP can be used to chronically suppress $\mathrm{InsP}_{3}$-mediated $\mathrm{Ca}^{2+}$ signals in astrocytes (Kanemaru et al., 2007). We adapted the same approach for chronic suppression of $\mathrm{InsP}_{3}$-mediated $\mathrm{Ca}^{2+}$ signals in PCs of $58 \mathrm{Q}$ mice. Two arginine residues (R343 and R350 in mouse Inpp5a sequence) have been previously demonstrated to be critical for catalytic activity of 5PP (Communi et al., 1996; Kanemaru et al., 2007). Replacing Arg343 with Ala (R343A) decreases the ability of 5PP 
to bind InsP $\mathrm{P}_{3}$, thus causing a 10 -fold increase in the $K_{\mathrm{m}}$ for $\mathrm{InsP}_{3}$ and consequently allowing partial suppression of IICR in cells when RA mutant is overexpressed (Communi et al., 1996; Kanemaru et al., 2007). A double R343A/ R350A mutation (DM) creates a null mutant of 5PP that is unable to suppress IICR and can be used as a negative control (Communi et al., 1996; Kanemaru et al., 2007).

We generated serotype 1 AAV viruses encoding HA-tagged versions of wild-type 5PP, RA, and DM mutants (Fig. 2A). In addition to $5 \mathrm{PP}$, these viruses also encoded EGFP protein to allow easy identification of infected cells by GFP fluorescence. In validation experiments, MEF cell cultures were infected with AAV-5PP viruses. Expression of recombinant 5PP in infected cells was confirmed by Western blotting of MEF cell lysates with anti-HA and anti5PP antibodies (Fig. 2B). To validate the functional effects of 5PP overexpression, we performed a series of fura- $2 \mathrm{Ca}^{2+} \mathrm{im}$ aging experiments with AAV-5PPinfected MEF cells. The AAV-GFP virus was used as an additional control in these experiments. Ins $\mathrm{P}_{3}$-coupled hormone $\mathrm{BK}$ was used to trigger IICR in these experiments. We found that the application of $300 \mathrm{~nm}$ BK resulted in strong $\mathrm{Ca}^{2+}$ responses in MEF cells infected with AAVGFP or AAV-DM viruses (Fig. 2C,D). Consistent with the previous report (Kanemaru et al., 2007), IICR was significantly suppressed in cells infected with AAV-RA viruses and was completely abolished in cells infected with AAV-5PP viruses (Fig. 2C,D).

Ins $\mathrm{P}_{3}$-mediated signaling is important for Purkinje cell function, and the genetic deletion of $\mathrm{InsP}_{3} \mathrm{R} 1$ results in severe epileptic phenotype and early death in mice (Matsumoto et al., 1996). To avoid such problems, we restricted our in vivo experiments to the less potent 5PP-RA mutant. The inactive 5PP-DM mutant was used as a negative control in these experiments. The AAV-RA and AAV-DM viruses were delivered by bilateral stereotaxic injection into the DCN region of 7-week-old WT and 58Q mice (Fig. 3A). PCs project axonal processes to the DCN and transport the virus load retrogradely to the cell body in the molecular layer of the cerebellar cortex. As previously described, this protocol effectively transduces PCs with recombinant AAV in vivo (Kaemmerer et al., 2000; Dodge et al., 2005). Indeed, in our experiments, we discovered that 2 weeks after AAV-GFP injection AAV-encoded GFP signal that can be detected in an average of $5.8 \pm 0.4$ cerebellar lobes and $71.1 \pm$ $4.6 \%$ PCs ( $n=17$ mice) (Fig. $3 C$ ). The cerebellar expression of Error bars indicate SEM.

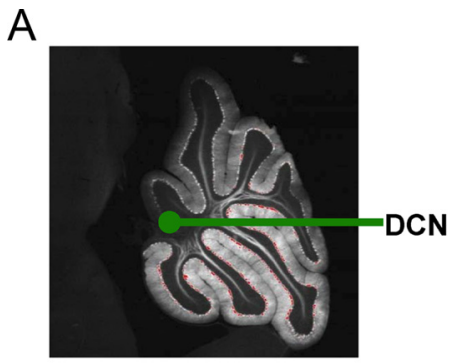

B

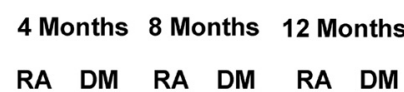

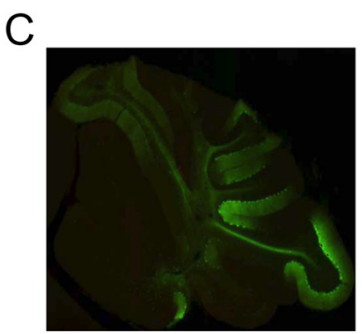

$2 X$

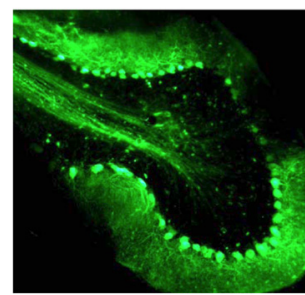

$10 x$
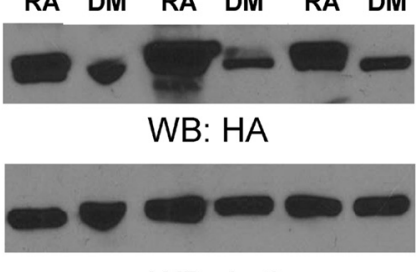

WB: Actin

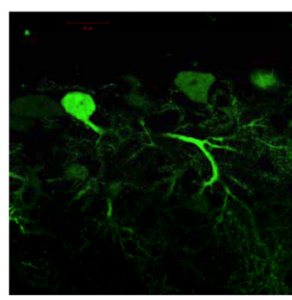

$60 X$
Figure 3. Chronic expression of 5PP in cerebellar Purkinje cells. $A, D C N$ injection protocol. Four microliters of $10^{13}$ infectious particles/ $\mu$ l was injected bilaterally into the DCN in the cerebellum of each mouse. Expression of GFP in transduced PCS was compared with expression of GFP in L7-GFP transgenic mice. Sample image of a 2-month-old L7-GFP is shown with $100 \%$ expression of the GFP transgene driven by the L7 pcp2 PC specific promoter. $B$, Relative protein expression of RA, DM, and actin was used as a loading control. Cerebellar lysates were prepared from injected mice at 4, 8, and 12 months. C, Transduction efficiency of DCN injection visualized by GFP imaging. Three weeks after AAV-5PP-RA virus was injected, mice were killed and cerebellar slices were imaged by GFP fluorescence.

\section{4 weeks}

A

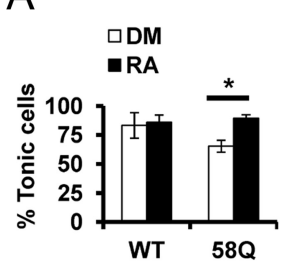

B

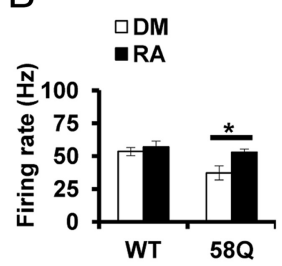

C

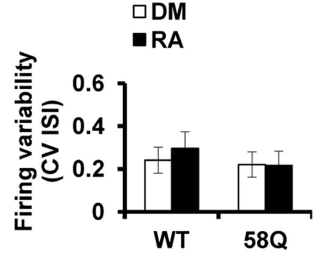

\section{8 weeks}

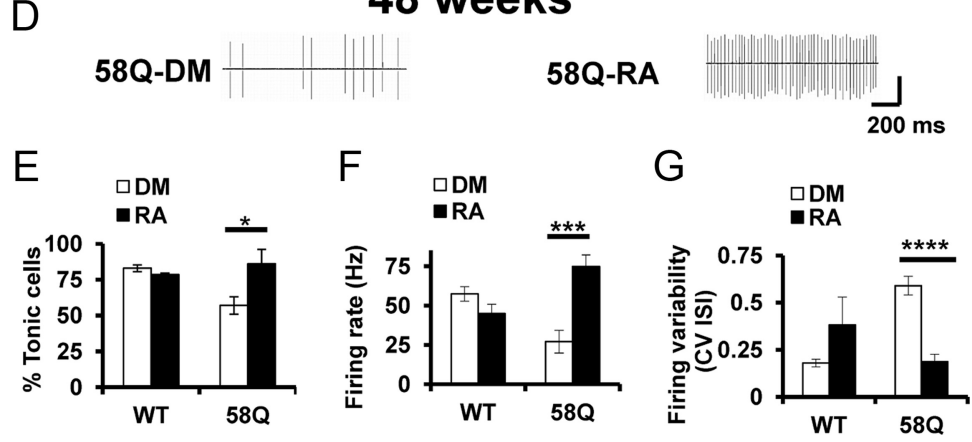

Figure 4. Effect of chronic suppression of Ins $\mathrm{P}_{3}$-mediated Calcium release in spontaneously active SCA2 Purkinje cells. $\boldsymbol{A}-\boldsymbol{C}$ Viral-mediated overexpression of RA rescues regular tonic firing in $58 \mathrm{PC}$. At 24 weeks of age, overexpression of AAV-RA in $58 \mathrm{Q}$ $P C$ increased the proportion of tonically firing cells $(\boldsymbol{A})$ and increased firing frequency of tonically firing cells $(\boldsymbol{B})$ and did not affect the firing variability of tonically firing cells (C). D, Sample $1 \mathrm{~s}$ traces of 48-week-old 58Q PC transduced with 5PP-DM or 5PP-RA. Overexpression of AAV-RA in 48-week-old $580 \mathrm{PC}$ s increased the proportion of tonically firing cells $(\boldsymbol{E})$, increased firing frequency of tonically firing cells $(\boldsymbol{F})$, and reduced the firing variability of tonically firing cells $(\boldsymbol{G}) .{ }^{*} p<0.05 ;{ }^{* * *} p<0.001 ;{ }^{* * *} p<0.0001$.

HA-tagged recombinant RA and DM constructs was further confirmed by immunohistochemistry using anti-HA antibodies (data not shown). Injection of AAV into the DCN at these coordinates leads to highest expression in the cerebellar lobules, with 
some expression in the DCN, pons, and medulla (Dodge et al., 2005). The continuous expression of RA and DM constructs in injected mice was confirmed by preparing cerebellar lysates from injected mice and probing with antibodies against the HA-tag (Fig. 3B).

\section{Suppressing $\mathrm{IP}_{3}$-induced calcium release prevents the progressive dysfunction of Purkinje cells in SCA2 mice}

To determine the effect of IICR suppression on the progressive dysfunction of PCs in the SCA2 mouse model, we injected the DCN of 7-week-old WT and 58Q mice with RA and DM viruses and prepared cerebellar slices from 24- and 48-week-old injected mice for the recording of spontaneous PC activity. The transduced cells in these experiments were identified by GFP imaging. At 24 weeks of age, we found that most 58Q PCs overexpressing RA fired spontaneous action potential currents in a tonic fashion with a firing frequency similar to WT PCs. Specifically, we observed that the overexpression of RA prevented the irregularity in firing patterns of transduced 58Q PCs (89\% tonically firing PCs; $n=27$ neurons; $n=3$ mice) when compared with 58Q-DM PCs (65\% tonically firing PCs; $n=34$ neurons; $n=4$ mice; Fig. $4 A$ ). The fraction of tonically firing RA-infected 58Q cells was similar to the fraction of tonically firing WT-DM PCs of the same age (83\% tonically firing PCs; $n=42$ neurons; $n=4$ mice; Fig. $4 A$ ). We also found that RA overexpression normalized the firing frequency and precision firing of tonically firing 58Q PCs (FF, $53 \pm$ $2.5 \mathrm{~Hz} ; p<0.001$; CV ISI, $0.22 \pm 0.07 ; n=22$ neurons) when compared with tonically firing 58Q-DM PCs (FF, $37 \pm 4.4 \mathrm{~Hz}$; CV ISI, $0.22 \pm 0.06 ; n=21$ neurons; Fig. $4 B, C)$. The fraction of tonically firing PC cells, the frequency of tonically firing cells and the variability of interspike interval were not significantly different between RA-transduced 58Q PC cells, RA-transduced WT PCs, and noninfected age-matched WT PC cells (Fig. 4A-C).

At 48 weeks, we found that most 58Q PCs overexpressing RA fired spontaneous action potential currents in a tonic fashion with a firing frequency similar to WT PCs. Specifically, we observed that the overexpression of $5 \mathrm{PP}$ prevented the irregularity in firing patterns of transduced 58Q PCs (86\% tonically firing PCs; $n=31$ neurons; $n=3$ mice) when compared with DMtransduced 58Q PCs (57\% tonically firing PCs; $n=19$ neurons; $n=2$ mice; Fig. $4 E$ ). The fraction of tonically firing RA-infected 58Q cells was similar to the fraction of tonically firing DMtransduced WT PCs of the same age (83\% tonically firing PCs; $n=16$ neurons; $n=2$ mice; Fig. $4 E$ ). We also found that RA overexpression restored the firing frequency and precision firing of 58Q PCs (FF, $75 \pm 7.4 \mathrm{~Hz}, p<0.001$; CV ISI, $0.19 \pm 0.04, p<$ $0.0001 ; n=25$ neurons) when compared with DM-transduced 58Q PCs (FF, $27 \pm 7.2 \mathrm{~Hz}$; CV ISI, $0.59 \pm 0.05 ; n=11$ neurons; Fig. $4 D-G)$. The fraction of tonically firing PC cells, the frequency of tonically firing cells, and the variability of interspike interval were not significantly different between RA-infected 58Q PC cells and noninfected age-matched WT PC cells (Fig. 4D-G). Interestingly, the overexpression of RA slightly reduced the firing frequency and impaired regularity of firing of WT PCs at this age (Fig. $4 E-G$ ), but the difference from noninfected WT cells was not statistically significant.

Calcium is an intracellular second messenger involved in a multitude of pathways downstream of $\mathrm{IP}_{3} \mathrm{Rs}$ (Kasumu and Bezprozvanny, 2012). A disruption in these pathways decreases cell health and stimulates cell death cascades. We believe that the PC dysfunction is a representation of declining cell health caused by excess calcium release. Thus, to study the efficacy of acute normalization of intracellular calcium in restoring normal PC func-
Table 1. Summary of in vivo study of the effect of 5PP overexpression on SCA2 phenotype

\begin{tabular}{lllccc}
\hline \multirow{5}{*}{ Group } & No. of & \multicolumn{4}{l}{ DCD measurements } \\
\cline { 3 - 6 } & animals & No. of & & & \\
\hline WT-DM & 13 & 171 & $81.1 \pm 6$ & $13 \pm 4$ & $5.9 \pm 2$ \\
WT-RA & 13 & 204 & $46 \pm 5^{*}$ & $35 \pm 3^{*}$ & $19 \pm 3^{*}$ \\
WT-NI & 15 & N/A & N/A & N/A & N/A \\
58Q-DM & 12 & 185 & $17 \pm 6^{* *}$ & $43 \pm 5$ & $40 \pm 8$ \\
58Q-RA & 19 & 218 & $62 \pm 7^{* *}$ & $28.3 \pm 6^{* *}$ & $9.76 \pm 4^{* *}$ \\
58Q-NI & 15 & N/A & N/A & N/A & N/A \\
\hline
\end{tabular}

Eighty-seven mice were genotyped, weight-matched, and divided into six groups. The allotted AAV virus was injected. The group number, group name, number, and genotype of mice in each group and AAV virus injected are shown for each group. Also shown are the mean whole-brain weights, cerebellar weights, and percentages of DCD status. N/A, Not applicable.

A two-tailed Student's unpaired $t$ test was used to judge differences between groups. There was a significant difference between $580-$ RA transduced PCs and 580-DM transduced PCs $\left({ }^{* *} p<0.01\right)$. There was a significant difference between WT-RA transduced PCs and WT-DM transduced PCs $\left({ }^{*} p<0.05\right)$. There was no significant difference between the DCD status of WT-DM PCs and 58Q-RA PCs.

tion, we tested the acute effect of blocking $\mathrm{IP}_{3}$-induced $\mathrm{Ca}^{2+}$ release in SCA2-58Q PCs. We treated 24-week-old slices from $58 \mathrm{Q}$ mice with an inhibitor of metabotropic glutamate receptors, LY367385. We found that $100 \mu \mathrm{M}$ LY367385 increased the firing frequency of 58Q PCs from $31.2 \pm 4$ to $40.1 \pm 4 \mathrm{~Hz}(n=14$ neurons) (data not shown). However, this was not statistically significant. Consequently, the acute treatment of 58Q PCs with LY367385 decreased the irregularity in firing of 58Q PCs from $0.10 \pm 0.02$ to $0.06 \pm 0.01$ ( $p<0.05 ; n=14$ neurons) (data not shown).

\section{Chronic 5PP overexpression prevents motor coordination deficits in SCA2 mice}

To determine whether preventing the PC dysfunction also reverses the motor incoordination in 58Q mice, WT and 58Q mice were divided into six groups (Table 1). Female WT and 58Q were age-matched and were used for this series of experiments. One group of WT mice and another group of 58Q mice underwent surgery for the DCN injection of AAV-RA. Two control groups were included that were injected with AAV-DM and two naive groups of mice were also included that never experienced any surgery [noninjected (NI)]. All six groups of mice were then tested in motor coordination assays over a 10 month period using the beam walk ( $11 \mathrm{~mm}$ round and $5 \mathrm{~mm}$ square beam) and accelerating rotarod behavioral tasks. Both tasks were performed starting at 2 months after surgery (i.e., with 4-, 6-, 8-, 10-, and 12-month-old mice). Previously, we reported that the onset of motor incoordination in 58Q mice (C57/B6 strain) is between 6 and 8 months of age (Liu et al., 2009). Consistent with this earlier finding, NI 58Q mice (FVB strain) used in the present study also demonstrated impaired beam walk performance starting at 6 months of age when compared with NI WT mice (Fig. 5). We further found that, at 6 months of age, $58 \mathrm{Q}$ mice injected with RA made significantly less foot slips on $5 \mathrm{~mm}$ square beam than NI 58Q and 58Q mice overexpressing DM (Fig. $5 F$ ). Starting at 8 months of age, the $58 \mathrm{Q}$ mice expressing RA made fewer errors while traversing the entire length of the 11 or $5 \mathrm{~mm}$ beam (Fig. $5 B, F)$ and had a shorter latency to traverse the 11 or $5 \mathrm{~mm}$ beam (Fig. $5 D, H$ ). There was no significant difference between the performance of 58Q-RA, WT-NI, and WT-DM mice (Fig. 5). SCA2-58Q mice expressing RA continued to perform significantly better on the 11 and $5 \mathrm{~mm}$ beam than $58 \mathrm{Q}$ mice expressing DM at the 8,10, and 12 month time points. Overexpression of RA in PCs of WT mice did not affect its performance on $11 \mathrm{~mm}$ beam 
(Fig. 5A,C). However, it increased the number of errors made on the $5 \mathrm{~mm}$ beam at 10 and 12 month time points (Fig. 5E) and increased the latency to traverse the entire $5 \mathrm{~mm}$ beam length at 8 months (Fig. $5 E, G$ ).

The same cohort of mice was also tested on the accelerating rotarod task. At 6 months of age, 58Q mice injected with RA performed significantly better on the rotarod task than 58Q-DM and 58Q-NI mice (Fig. 6B). There was no significant difference between the performance of $58 \mathrm{Q}$ mice expressing RA and WT mice expressing DM (Fig. 6A,B). 58Q mice expressing $\mathrm{RA}$ continued to perform significantly better on the rotarod than $58 \mathrm{Q}$ mice expressing DM at the 8, 10, and 12 month time points. WT mice expressing RA had a trend to perform worse on the rotarod than WT-NI mice and WT-DM mice (Fig. 6A). However, this difference was not statistically significant. We monitored the body weight of all the mice in this study and did not find any significant differences between the six groups at all ages (data not shown). From these experiments, we concluded that partial and chronic suppression of IICR in PCs of 58Q mice resulted in significantly improved beam walk and rotarod performance and that the same manipulation in PCs of WT mice resulted in somewhat impaired beam walk and rotarod performance.

\section{Chronic 5PP overexpression alleviates PC cell pathology in SCA2 mice}

To assess whether the benefit of chronic 5PP-RA overexpression also extended to preventing SCA2-58Q pathology, this cohort of mice was killed at 12 months of age for pathological analysis. We previously reported that calbindin staining and stereological counting of PCs only detected a $15 \%$ loss of PCs in 12-month-old 58Q mice (Liu et al., 2009). An alternative method used to analyze PC health status is by the quantification of DCD. DCD is a form of cell death induced by excitotoxicity, which has been used previously to assess the health state of PCs in mouse models of SCA7 and SCA28 (Barenberg et al., 2001; Strahlendorf et al., 2003; Custer et al., 2006; Maltecca et al., 2009). Using this method in previous studies, we demonstrated that DCD quantification is a more sensitive way to analyze PC death in SCA2 mice (Kasumu and Bezprozvanny, 2012). We previously reported that, at 12 months of age, $<20 \%$ of PCs in $58 \mathrm{Q}$ mice appear normal, compared with $70 \%$ of PCs in agematched nontransgenic mice (Kasumu and Bezprozvanny, 2012).

To analyze DCD, cerebellar sections from each of six experimental groups of mice (Table 1) were processed for transmission electron ${ }^{* * *} p<0.001$.
WT

\section{$11 \mathrm{~mm}$ beam}
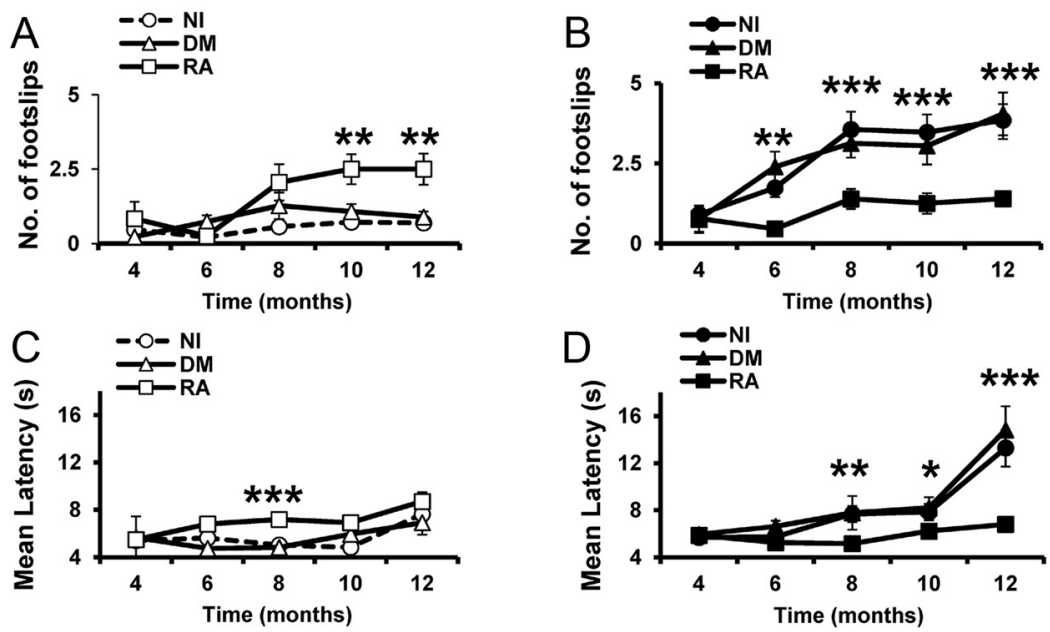

$5 \mathrm{~mm}$ beam
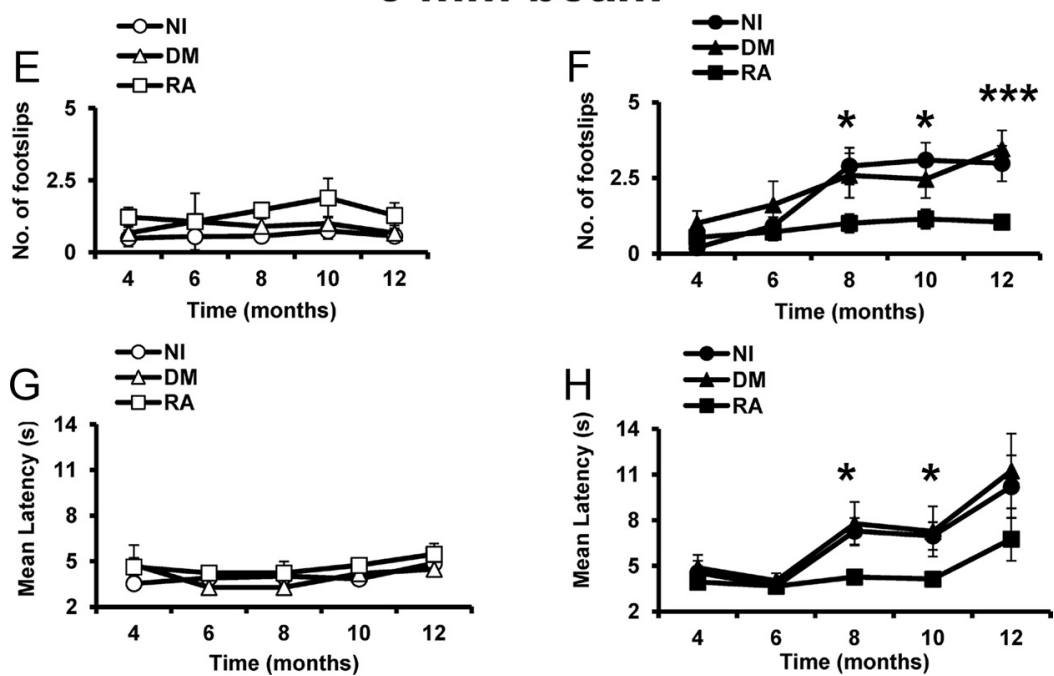

Figure 5. Effect of 5PP chronic overexpression on beam walk performance of SCA2 mice. Performance on the $11 \mathrm{~mm}$ round beam $(\boldsymbol{A}-\boldsymbol{D})$ and $5 \mathrm{~mm}$ square beam $(\boldsymbol{E}-\boldsymbol{H})$ was measured every 2 months. $\boldsymbol{A}, \boldsymbol{B}$, Average number of foot slips as the mice traverse the entire length of the $11 \mathrm{~mm}$ beam is plotted for the NI, RA-injected, and DM-injected WT and 580 mice as mean \pm SE from 4 to 12 months. 580 mice injected with RA made fewer errors on the $11 \mathrm{~mm}$ beam than 580 mice injected with DM and NI 580 mice. C, $D$, Average time to traverse the entire length of the $11 \mathrm{~mm}$ beam is plotted for all six groups as mean \pm SE from 4 to 12 months. 580 mice injected with RA traversed the $5 \mathrm{~mm}$ beam faster than their 580 counterparts and as fast as WT mice injected with DM and naive WT mice. Performance on the $5 \mathrm{~mm}$ beam was analyzed and recorded every 2 months. $\boldsymbol{E}$, $\boldsymbol{F}$, Average number of foot slips as the mice traverse the entire length of the $11 \mathrm{~mm}$ beam is plotted for the NI, RA-injected, and DM-injected WT and 580 mice as mean \pm SE from 4 to 12 months. 580 mice injected with RA made fewer errors on the $5 \mathrm{~mm}$ beam than 580 mice injected with DM and NI $58 \mathrm{Q}$ mice. $\boldsymbol{G}, \boldsymbol{H}$, Average time to traverse the entire length of the $5 \mathrm{~mm}$ beam is plotted for all six groups as mean \pm SE from 4 to 12 months. $58 \mathrm{Q}$ mice injected with RA traversed the $11 \mathrm{~mm}$ beam faster than their $58 \mathrm{Q}$ counterparts and as fast as WT mice injected with DM and naive WT mice. WT-RA mice also showed impairment in beam walk performance. ${ }^{*} p<0.05 ;{ }^{* *} p<0.01$;

microscopy (TEM), and the number of normal, moderately degenerated, and severely degenerated PCs was quantified. According to Custer et al. (2006) and Kasumu and Bezprozvanny (2012), PCs spherical in shape and with regular alignment in the PC layer were classified as "normal" (Fig. 7A). PCs with slight shrinkage compared with surrounding PCs and with moderately electron-dense cytosol that is not as dark as nucleus were classified as "moderate" (Fig. 7A). PCs with markedly shrunken and electron-dense cytosol with similarly darkened nucleus were classified as "severe" (Fig. 7A). In our analysis, we discovered that the expression of RA in 58Q mice signif- 


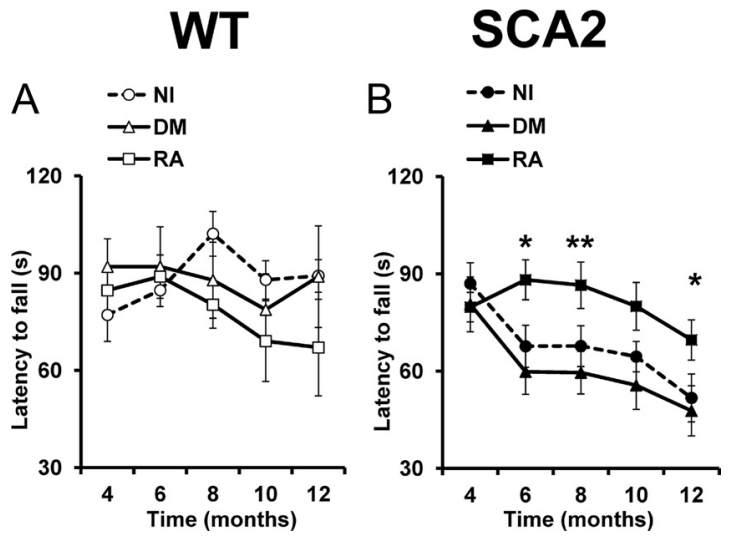

Figure 6. Effect of 5PP chronic overexpression on rotarod performance of SCA2 mice. $A, B$, The mice were tested on the accelerating rotarod at $0.2 \mathrm{rpm} / \mathrm{s}$. Average latency to fall from the accelerating rotarod is plotted for all six groups as mean \pm SE from 4 to 12 months of age. The onset of rotarod deficits in 580 mice injected with RA was prevented. ${ }^{*} p<0.05 ;{ }^{* *} p<0.01$.

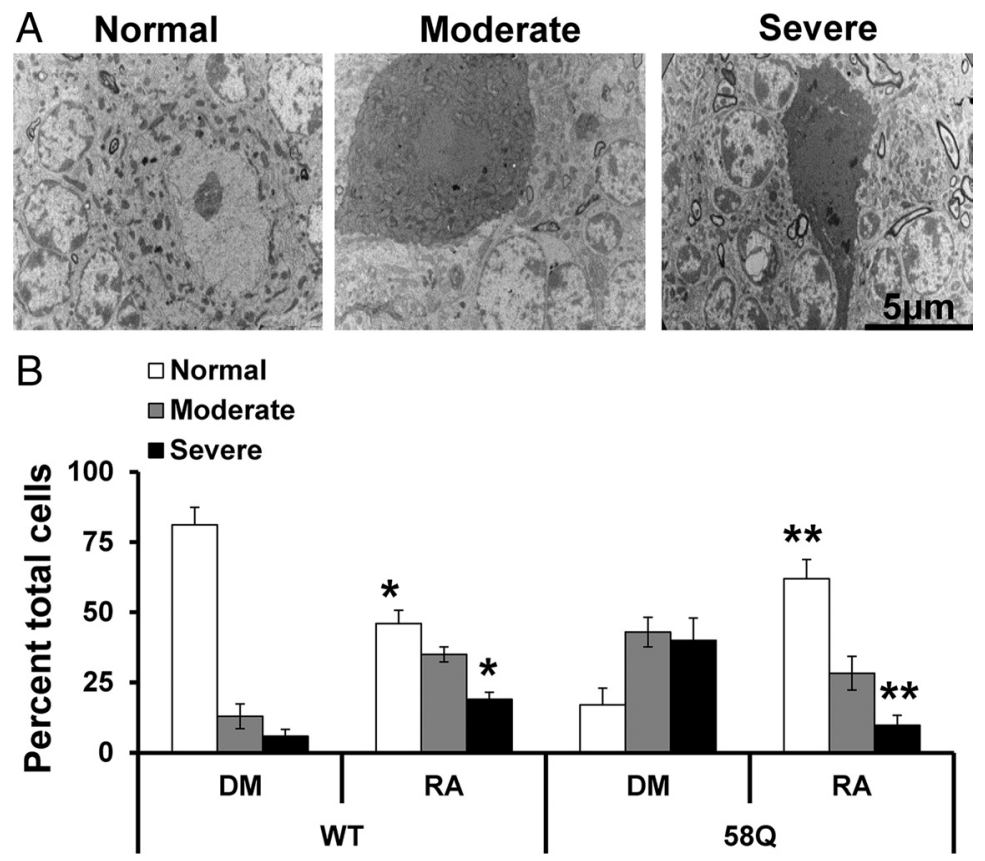

Figure 7. Effect of 5PP chronic overexpression on pathology of Purkinje cells in SCA2 mice. Cerebellar sections prepared from 48-week-old mice from each group were processed for TEM and analyzed for DCD. A, Representative TEM images of normal, moderately degenerated, and severely degenerated $\mathrm{PC} s$. $\boldsymbol{B}$, The fraction of normal, moderately degenerated, and severely degenerated PCs in RA-injected and DM-injected WT and 580 mice was quantified for each group of mice at 48 weeks of age. The overexpression of RA in 580 mice prevented dark cell degeneration of PCS. The overexpression of RA in WT mice caused an increase in dark cell degeneration of PCs. ${ }^{*} p<0.05 ;{ }^{* *} p<0.01$. Error bars indicate SEM.

icantly increased the percentage of normal PCs when compared with DM-injected 58Q mice (Fig. 7B). On average, in samples from RAinjected $58 \mathrm{Q}$ mice, $54 \%$ of PCs were normal, $29 \%$ were moderately degenerated, and $17 \%$ were severely degenerated $(n=218$ PCs; Fig. $7 B$, Table 1). In contrast, in samples from DM-injected $58 \mathrm{Q}$ mice, $12 \%$ of PCs were normal, $47 \%$ were moderately degenerated, and $41 \%$ were severely degenerated ( $n=185$ PCs; Fig. 7B, Table 1$)$. When compared with 58Q-DM mice, the increase in the fraction of normal cells and the reduction in the fraction of severely degenerated cells in 58Q-RA mice were statistically significant $(p<0.05$; Fig. $7 B$, Table 1). Interestingly, and in sharp contrast to $58 \mathrm{Q}$ mice, RA expression in WT PCs resulted in obvious worsening of DCD phenotype (Fig. $7 B$, Table 1).

\section{Discussion \\ Dysfunction of Purkinje cells in SCA2 and other cerebellar ataxias}

It is generally assumed that neuronal dysfunction before symptom presentation is a common occurrence in cerebellar ataxias (Walter et al., 2006; Alviña and Khodakhah, 2010a,b; Mark et al., 2011; Shakkottai et al., 2011; Kasumu and Bezprozvanny, 2012). However, only a few functional studies of PCs in ataxia mouse models have been performed. In a recent study, PCs in presymptomatic SCA3 mice were reported to fire less tonically than PCs in WT mice (Shakkottai et al., 2011). PCs in mouse models of episodic ataxia fire less regularly than PCs in age-matched wild-type mice (Walter et al., 2006; Alviña and Khodakhah, 2010a,b). Recent studies also demonstrated significantly reduced firing frequency of PCs in aging SCA2-127Q mice (S. Hansen, P. Meera, T. Otis, S. Pulst, unpublished observations). These findings agree with results that we obtained for PC spontaneous firing in the SCA2-58Q mouse model (Fig. 1). We discovered that the fraction of tonically firing PCs is lower in SCA2 mice when compared with age-matched wild-type mice (Fig. 1C). We further discovered that for the aging tonically firing SCA2 PC cells the frequency of firing is reduced (Fig. 1D) and variability of interspike intervals is increased (Fig. 1E) when compared with age-matched wild-type cells. Interestingly, the age of onset of electrophysiological abnormalities in 58Q PCs at 24 weeks of age (Fig. $1 C, D$ ) closely mirrors the age of onset of behavioral symptoms in SCA258Q mice in previous (Liu et al., 2009) and present (Figs. 5, 6) studies. The findings obtained in our study (Fig. 1) and in previous analyses of ataxic mouse models (Alviña and Khodakhah, 2010a,b; Shakkottai et al., 2011) support the hypothesis that the burst firing of PCs reflects the dysfunctional state of these cells and is directly linked with ataxic symptoms. This conclusion is in agreement with the well established importance of PC firing for maintaining cerebellar timing and function (Walter et al., 2006).

\section{Calcium hypothesis of SCA2 and other cerebellar ataxias}

What is the cause of neuronal dysfunction and death in cerebellar ataxias? In previous studies, we suggested that supranormal InsP $\mathrm{P}_{3} \mathrm{R}$-mediated $\mathrm{Ca}^{2+}$ release from the ER may play an important role in pathogenesis of SCA2 and SCA3 (Chen et al., 2008; Liu et al., 2009). Based on these results, we proposed a "calcium hypothesis" of cerebellar ataxias (Kasumu and Bezprozvanny, 2012). Genetic analysis was used by another group to independently suggest an importance of $\mathrm{Ins}_{3}$-mediated $\mathrm{Ca}^{2+}$ signaling in the pathogenesis of many SCAs (Schorge et al., 2010). We also demonstrated the neuroprotective effects of dantrolene, $\mathrm{a} \mathrm{Ca}^{2+}$ stabilizer, in SCA3 and SCA2 mouse models (Chen et al., 2008; Liu et al., 2009). In the present study, we used a highly specific molecular tool to further test " $\mathrm{Ca}^{2+}$ hypothesis" in the SCA2 mouse model. By using an adenoassociated viral approach, we achieved stable expression of 5PP enzyme in PCs of SCA2 transgenic 
mouse model. The 5PP enzyme converts the active messenger $\operatorname{Ins}_{3}$ to its inactive InsP $\mathrm{P}_{2}$ form. As it has been demonstrated previously (Kanemaru et al., 2007), heterologous overexpression of 5PP results in potent inhibition of $\mathrm{InsP}_{3} \mathrm{R}$-mediated $\mathrm{Ca}^{2+}$ signaling in cells. In our experiments, we used the partially active R343A mutant of 5PP (RA) with reduced enzymatic activity. We reasoned that chronic expression of RA mutant in SCA2 PCs will normalize supranormal InsP $\mathrm{P}_{3} \mathrm{R}$-mediated $\mathrm{Ca}^{2+}$ signals in SCA2 PCs without completely suppressing them. The catalytically inactive double mutant 5PP-DM was used in our studies as a negative control. Consistent with our predictions, we found that chronic expression of RA in SCA2 PCs normalized their electrophysiological phenotype (Fig. 4), alleviated motor coordination deficit of SCA2 mice in beam walk and rotarod assays (Figs. 5, 6), and prevented DCD form of PC death in aging SCA2 mice (Fig. 7, Table 1). These effects required the enzymatic activity of 5PP, as the chronic expression of the catalytically dead R343A/R350A mutant 5PP (DM) had no effect in behavioral assays with SCA2 mice (Figs. 5, 6) and did not protect SCA2 PC cells in DCD assay (Fig. 7). These findings provided strong support for the "calcium hypothesis of SCA2" and suggested that partial inhibition of $\mathrm{InsP}_{3}$-mediated $\mathrm{Ca}^{2+}$ signaling could provide therapeutic benefit for the patients afflicted with SCA2 and possibly other SCAs.

\section{Ins $\mathrm{P}_{3}$-induced $\mathrm{Ca}^{2+}$ release and control of autophagy}

Autophagy plays an important role in neurodegenerative disorders (Ravikumar et al., 2010). Previous studies have shown that decreasing total $\mathrm{InsP}_{3}$ levels with agents such as lithium [inhibits inositol recycling (Shakkottai et al., 2001)], L-690330 ([1-(4hydroxyphenoxy)ethylidene] bisphosphonic acid) [inhibits inositol recycling (Simon et al., 2010)], valproic acid [inhibits inositol biosynthesis (Kuznetsov et al., 2006)], and cytosolic InsP $_{3}$ kinase A [diminishes total $\mathrm{InsP}_{3}$ (Simon et al., 2010)] induces autophagy. Studies have also shown that $\mathrm{Ins}_{3} \mathrm{R}$ inhibition with Xestospongin B (Ito, 2002) or InsP ${ }_{3}$ R knockdown by siRNA (Fouquet et al., 2011) strongly stimulated autophagy. Thus, it is possible that chronic overexpression of 5PP in our experiments acted by stimulating autophagy in SCA2 PCs by reducing $\mathrm{InsP}_{3}$ levels. The 5PP intervention functions by hydrolyzing $\operatorname{Ins}_{3}$ after it is produced (Kanemaru et al., 2007). Thus, 5PP overexpression only decreases the lifetime of cytosolic $\mathrm{InsP}_{3}$ without affecting Ins $\mathrm{P}_{3}$ production or changing levels of phosphoinositides present in the membrane. There is no evidence in the literature for the direct involvement of $\mathrm{InsP}_{3}$ in upregulating autophagy, and the inhibition of autophagy appears to be another downstream mechanism of excessive $\mathrm{Ca}^{2+}$ release (Laver and Lamb, 1998; Brady et al., 2007; Decuypere et al., 2011a,b; Hosy et al., 2011). Therefore, beneficial effects of our 5PP intervention in SCA2$58 \mathrm{Q}$ mice arose primarily from suppressing excessive $\mathrm{Ca}^{2+}$ release from the ER in PCs cells, with possible downstream effects of $\mathrm{Ca}^{2+}$ on the autophagy along with effects of $\mathrm{Ca}^{2+}$ on mito- chondrial dysfunction, calpain activation, and other $\mathrm{Ca}^{2+}$. dependent cellular processes.

\section{Importance of Ins $\mathrm{P}_{3} \mathrm{R}$-mediated $\mathrm{Ca}^{2+}$ signaling for Purkinje} cell function

Our results indicate that excessive $\mathrm{Ca}^{2+}$ release from $\operatorname{Ins} \mathrm{P}_{3} \mathrm{R}$ sensitive $\mathrm{Ca}^{2+}$ stores is likely to play a key role in dysfunction and eventual death of PCs in SCA2. This conclusion is consistent with early-onset PC degeneration and the ataxic phenotype in Inpp5a (5PP) knock-out mice (Yang et al., 2010). The 5PP enzyme is highly expressed in cerebellar PCs; thus, it is likely that knock-out of 5PP causes delayed termination of $\mathrm{Ins}_{3}$ signals and supranormal $\mathrm{Ca}^{2+}$ release. Remarkably, insufficient $\mathrm{InsP}_{3} \mathrm{R}$-mediated $\mathrm{Ca}^{2+}$ signaling also leads to the ataxic phenotype and PC degeneration, such as observed in SCA15/16 patients haploinsufficient for the InsP $\mathrm{P}_{3} \mathrm{R} 1$ gene (van de Leemput et al., 2007; Hara et al., 2008; Iwaki et al., 2008). An ataxic phenotype is also observed in opt mice with reduced levels of $\mathrm{InsP}_{3} \mathrm{R} 1$ protein (Street et al., 1997), and a severe ataxia is observed in $\mathrm{InsP}_{3} \mathrm{R} 1$ knock-out mice (Matsumoto et al., 1996). These findings indicate that the reduced $\mathrm{Ca}^{2+}$ release via InsP $\mathrm{P}_{3} \mathrm{R} 1$ also leads to PC dysfunction and ataxic phenotype. Some of the data in the present manuscript support this conclusion. Despite using the RA version of 5PP with reduced activity in our experiments, we observed that chronic expression of RA in wild-type PC cells resulted in mild impairment in the precision of PC firing (Fig. 4G), impaired beam walk, and rotarod performance of wild-type mice in behavioral studies (Figs. 5, 6) and a reduced fraction of normal cells in DCD analysis of wild-type mice (Fig. $7 B$, Table 1). Although relatively mild, these effects were in sharp contrast with the beneficial effects of RA expression in SCA2-58Q mice (Figs. 4-7, Table 1).

We conclude from these findings that there is a relatively narrow range of optimal $\mathrm{Ins}_{3}$-mediated $\mathrm{Ca}^{2+}$ signaling that is compatible with proper function and long-term survival of PCs. Deviation from this optimal range in either direction of $\mathrm{InsP}_{3}$ mediated $\mathrm{Ca}^{2+}$ signaling results in $\mathrm{PC}$ dysfunction and an ataxic phenotype. According to this model (Fig. 8), supranormal $\mathrm{InsP}_{3}$ mediated $\mathrm{Ca}^{2+}$ signals are responsible for PC dysfunction and ataxic phenotype in SCA2 patients, as well as in Inpp5a knock- 
out mice (Fig. 8). The subnormal $\mathrm{InsP}_{3}$-mediated $\mathrm{Ca}^{2+}$ signals are likely responsible for PC dysfunction and the ataxic phenotype in SCA15/16 patients and InsP $\mathrm{P}_{3} \mathrm{R} 1$ knock-out mice (Fig. 8). Chronic expression of 5PP-RA enzyme in our studies shifted $\mathrm{Ca}^{2+}$ signals in SCA-58Q PCs to a normal range and rescued the SCA2 phenotype (Fig. 8). However, chronic expression of the same enzyme in WT PC cells in our studies shifted $\mathrm{Ca}^{2+}$ signals to subnormal range, resulting is detrimental effects (Fig. 8). This hypothesis agrees well with independent genetic evidence that placed InsP $\mathrm{P}_{3} \mathrm{R}$ in the eye of the storm of pathogenesis for many SCAs (Schorge et al., 2010).

\section{References}

Alviña K, Khodakhah K (2010a) KCa channels as therapeutic targets in episodic ataxia type-2. J Neurosci 30:7249-7257.

Alviña K, Khodakhah K (2010b) The therapeutic mode of action of 4-aminopyridine in cerebellar ataxia. J Neurosci 30:7258-7268.

Barenberg P, Strahlendorf H, Strahlendorf J (2001) Hypoxia induces an excitotoxic-type of dark cell degeneration in cerebellar Purkinje neurons. Neurosci Res 40:245-254.

Bezprozvanny I, Klockgether T (2010) Therapeutic prospects for spinocerebellar ataxia type 2 and 3. Drugs Future 34:991-999.

Brady NR, Hamacher-Brady A, Yuan H, Gottlieb RA (2007) The autophagic response to nutrient deprivation in the hl-1 cardiac myocyte is modulated by $\mathrm{Bcl}-2$ and sarco/endoplasmic reticulum calcium stores. FEBS J 274:3184-3197.

Bürk K, Abele M, Fetter M, Dichgans J, Skalej M, Laccone F, Didierjean O, Brice A, Klockgether T (1996) Autosomal dominant cerebellar ataxia type I clinical features and MRI in families with SCA1, SCA2 and SCA3. Brain 119:1497-1505.

Chen X, Tang TS, Tu H, Nelson O, Pook M, Hammer R, Nukina N, Bezprozvanny I (2008) Deranged calcium signaling and neurodegeneration in spinocerebellar ataxia type 3. J Neurosci 28:12713-12724.

Communi D, Motte S, Boeynaems JM, Pirotton S (1996) Pharmacological characterization of the human P2Y4 receptor. Eur J Pharmacol 317:383-389.

Custer SK, Garden GA, Gill N, Rueb U, Libby RT, Schultz C, Guyenet SJ, Deller T, Westrum LE, Sopher BL, La Spada AR (2006) Bergmann glia expression of polyglutamine-expanded ataxin-7 produces neurodegeneration by impairing glutamate transport. Nat Neurosci 9:1302-1311.

Decuypere JP, Bultynck G, Parys JB (2011a) A dual role for $\mathrm{Ca}^{2+}$ in autophagy regulation. Cell Calcium 50:242-250.

Decuypere JP, Welkenhuyzen K, Luyten T, Ponsaerts R, Dewaele M, Molgó J, Agostinis P, Missiaen L, De Smedt H, Parys JB, Bultynck G (2011b) Ins $(1,4,5) \mathrm{P} 3$ receptor-mediated $\mathrm{Ca}^{2+}$ signaling and autophagy induction are interrelated. Autophagy 7:1472-1489.

Dodge JC, Clarke J, Song A, Bu J, Yang W, Taksir TV, Griffiths D, Zhao MA, Schuchman EH, Cheng SH, O'Riordan CR, Shihabuddin LS, Passini MA, Stewart GR (2005) Gene transfer of human acid sphingomyelinase corrects neuropathology and motor deficits in a mouse model of NiemannPick type A disease. Proc Natl Acad Sci U S A 102:17822-17827.

Fouquet C, Petit GH, Auffret A, Gaillard E, Rovira C, Mariani J, Rondi-Reig L (2011) Early detection of age-related memory deficits in individual mice. Neurobiol Aging 32:1881-1895.

Geschwind DH, Perlman S, Figueroa CP, Treiman LJ, Pulst SM (1997) The prevalence and wide clinical spectrum of the spinocerebellar ataxia type 2 trinucleotide repeat in patients with autosomal dominant cerebellar ataxia. Am J Hum Genet 60:842-850.

Hara K, Shiga A, Nozaki H, Mitsui J, Takahashi Y, Ishiguro H, Yomono H, Kurisaki H, Goto J, Ikeuchi T, Tsuji S, Nishizawa M, Onodera O (2008) Total deletion and a missense mutation of ITPR1 in Japanese SCA15 families. Neurology 71:547-551.

Häusser M, Clark BA (1997) Tonic synaptic inhibition modulates neuronal output pattern and spatiotemporal synaptic integration. Neuron 19:665-678.

Herreman A, Serneels L, Annaert W, Collen D, Schoonjans L, De Strooper B (2000) Total inactivation of gamma-secretase activity in presenilindeficient embryonic stem cells. Nat Cell Biol 2:461-462.

Hosy E, Piochon C, Teuling E, Rinaldo L, Hansel C (2011) SK2 channel expression and function in cerebellar Purkinje cells. J Physiol 589:3433-3440.
Huynh DP, Figueroa K, Hoang N, Pulst SM (2000) Nuclear localization or inclusion body formation of ataxin-2 are not necessary for SCA2 pathogenesis in mouse or human. Nat Genet 26:44-50.

Imbert G, Saudou F, Yvert G, Devys D, Trottier Y, Garnier JM, Weber C, Mandel JL, Cancel G, Abbas N, Dürr A, Didierjean O, Stevanin G, Agid Y, Brice A (1996) Cloning of the gene for spinocerebellar ataxia 2 reveals a locus with high sensitivity to expanded CAG/glutamine repeats. Nat Genet 14:285-291.

Ito M (2002) Historical review of the significance of the cerebellum and the role of Purkinje cells in motor learning. Ann N Y Acad Sci 978:273-288.

Iwaki A, Kawano Y, Miura S, Shibata H, Matsuse D, Li W, Furuya H, Ohyagi Y, Taniwaki T, Kira J, Fukumaki Y (2008) Heterozygous deletion of ITPR1, but not SUMF1, in spinocerebellar ataxia type 16. J Med Genet 45:32-35.

Kaemmerer WF, Reddy RG, Warlick CA, Hartung SD, McIvor RS, Low WC (2000) In vivo transduction of cerebellar Purkinje cells using adenoassociated virus vectors. Mol Ther 2:446-457.

Kanemaru K, Okubo Y, Hirose K, Iino M (2007) Regulation of neurite growth by spontaneous $\mathrm{Ca}^{2+}$ oscillations in astrocytes. J Neurosci 27:8957-8966.

Kasumu A, Bezprozvanny I (2012) Deranged calcium signaling in Purkinje cells and pathogenesis in spinocerebellar ataxia 2 (SCA2) and other ataxias. Cerebellum 11:630-639.

Kuznetsov AS, Kopell NJ, Wilson CJ (2006) Transient high-frequency firing in a coupled-oscillator model of the mesencephalic dopaminergic neuron. J Neurophysiol 95:932-947.

Lastres-Becker I, Rüb U, Auburger G (2008) Spinocerebellar ataxia 2 (SCA2). Cerebellum 7:115-124.

Laver DR, Lamb GD (1998) Inactivation of $\mathrm{Ca}^{2+}$ release channels (ryanodine receptors RyR1 and RyR2) with rapid steps in $\left[\mathrm{Ca}^{2+}\right]$ and voltage. Biophys J 74:2352-2364.

Liu J, Tang TS, Tu H, Nelson O, Herndon E, Huynh DP, Pulst SM, Bezprozvanny I (2009) Deranged calcium signaling and neurodegeneration in spinocerebellar ataxia type 2. J Neurosci 29:9148-9162.

Maltecca F, Magnoni R, Cerri F, Cox GA, Quattrini A, Casari G (2009) Haploinsufficiency of AFG3L2, the gene responsible for spinocerebellar ataxia type 28 , causes mitochondria-mediated Purkinje cell dark degeneration. J Neurosci 29:9244-9254.

Mark MD, Maejima T, Kuckelsberg D, Yoo JW, Hyde RA, Shah V, Gutierrez D, Moreno RL, Kruse W, Noebels JL, Herlitze S (2011) Delayed postnatal loss of P/Q-type calcium channels recapitulates the absence epilepsy, dyskinesia, and ataxia phenotypes of genomic Cacnala mutations. J Neurosci 31:4311-4326.

Matsumoto M, Nakagawa T, Inoue T, Nagata E, Tanaka K, Takano H, Minowa O, Kuno J, Sakakibara S, Yamada M, Yoneshima H, Miyawaki A, Fukuuchi Y, Furuichi T, Okano H, Mikoshiba K, Noda T (1996) Ataxia and epileptic seizures in mice lacking type 1 inositol 1,4,5-trisphosphate receptor. Nature 379:168-171.

Pulst SM, Nechiporuk A, Nechiporuk T, Gispert S, Chen XN, Lopes-Cendes I, Pearlman S, Starkman S, Orozco-Diaz G, Lunkes A, DeJong P, Rouleau GA, Auburger G, Korenberg JR, Figueroa C, Sahba S (1996) Moderate expansion of a normally biallelic trinucleotide repeat in spinocerebellar ataxia type 2. Nat Genet 14:269-276.

Ravikumar B, Sarkar S, Davies JE, Futter M, Garcia-Arencibia M, GreenThompson ZW, Jimenez-Sanchez M, Korolchuk VI, Lichtenberg M, Luo S, Massey DC, Menzies FM, Moreau K, Narayanan U, Renna M, Siddiqi FH, Underwood BR, Winslow AR, Rubinsztein DC (2010) Regulation of mammalian autophagy in physiology and pathophysiology. Physiol Rev 90:1383-1435.

Sanpei K, Takano H, Igarashi S, Sato T, Oyake M, Sasaki H, Wakisaka A, Tashiro K, Ishida Y, Ikeuchi T, Koide R, Saito M, Sato A, Tanaka T, Hanyu S, Takiyama Y, Nishizawa M, Shimizu N, Nomura Y, Segawa M, et al. (1996) Identification of the spinocerebellar ataxia type 2 gene using a direct identification of repeat expansion and cloning technique, DIRECT. Nat Genet 14:277-284.

Schorge S, van de Leemput J, Singleton A, Houlden H, Hardy J (2010) Human ataxias: a genetic dissection of inositol triphosphate receptor (ITPR1)-dependent signaling. Trends Neurosci 33:211-219.

Shakkottai VG, Regaya I, Wulff H, Fajloun Z, Tomita H, Fathallah M, Cahalan MD, Gargus JJ, Sabatier JM, Chandy KG (2001) Design and characterization of a highly selective peptide inhibitor of the small conductance calciumactivated $\mathrm{K}^{+}$channel, SkCa2. J Biol Chem 276:43145-43151. 
Shakkottai VG, do Carmo Costa M, Dell'Orco JM, Sankaranarayanan A, Wulff H, Paulson HL (2011) Early changes in cerebellar physiology accompany motor dysfunction in the polyglutamine disease spinocerebellar ataxia type 3. J Neurosci 31:13002-13014.

Simon KC, Gao X, Chen H, Schwarzschild MA, Ascherio A (2010) Calcium channel blocker use and risk of Parkinson's disease. Mov Disord 25:1818-1822.

Smith SL, Otis TS (2003) Persistent changes in spontaneous firing of Purkinje neurons triggered by the nitric oxide signaling cascade. J Neurosci 23:367-372.

Strahlendorf J, Box C, Attridge J, Diertien J, Finckbone V, Henne WM, Medina MS, Miles R, Oomman S, Schneider M, Singh H, Veliyaparambil M, Strahlendorf H (2003) AMPA-induced dark cell degeneration of cerebellar Purkinje neurons involves activation of caspases and apparent mitochondrial dysfunction. Brain Res 994:146-159.

Street VA, Bosma MM, Demas VP, Regan MR, Lin DD, Robinson LC, Agnew
WS, Tempel BL (1997) The type 1 inositol 1,4,5-trisphosphate receptor gene is altered in the opisthotonos mouse. J Neurosci 17:635-645.

Tu H, Nelson O, Bezprozvanny A, Wang Z, Lee SF, Hao YH, Serneels L, De Strooper B, Yu G, Bezprozvanny I (2006) Presenilins form ER calcium leak channels, a function disrupted by mutations linked to familial Alzheimer's disease. Cell 126:981-993.

van de Leemput J, Chandran J, Knight MA, Holtzclaw LA, Scholz S, Cookson MR, Houlden H, Gwinn-Hardy K, Fung HC, Lin X, Hernandez D, SimonSanchez J, Wood NW, Giunti P, Rafferty I, Hardy J, Storey E, Gardner RJ, Forrest SM, Fisher EM, et al. (2007) Deletion at ITPR1 underlies ataxia in mice and spinocerebellar ataxia 15 in humans. PLoS Genet 3:e108.

Walter JT, Alviña K, Womack MD, Chevez C, Khodakhah K (2006) Decreases in the precision of Purkinje cell pacemaking cause cerebellar dysfunction and ataxia. Nat Neurosci 9:389-397.

Yang AW, Sachs AJ, Nystuen AM (2010) Mutation in Inpp5a results in Purkinje cell degeneration and ataxia in the mouse. Soc Neurosci Abstr 36:253.9. 